\title{
The Importance of Extensor Mechanism in the Success of Patello-Femoral Arthroplasty
}

\author{
Rajkumar Krishnan, Ray Randle \\ John Flynn Medical Center, Gold Coast, Australia \\ Email: skrk77@gmail.com
}

Received 7 June 2014; revised 22 July 2014; accepted 5 August 2014

Copyright (C) 2014 by authors and Scientific Research Publishing Inc.

This work is licensed under the Creative Commons Attribution International License (CC BY). http://creativecommons.org/licenses/by/4.0/

c) (i) Open Access

\begin{abstract}
Anterior knee pain is a common symptom in general orthopedic practice and is reported in $8 \%$ of women and $2 \%$ of men over the age of 55 years. The treatment of isolated patellofemoral arthritis is controversial. Many patients can be effectively managed conservatively. Analysis was done on 14 patients (17 knees) with symptomatic isolated patellofemoral osteoarthritis between 2001 and 2007. 3 patients had additional procedures like tibial tubercle osteotomy and lateral release, tibial tubercle osteotomy with medical plication and iliotibial band lengthening and lateral retinacular release. The operation should be viewed as a soft-tissue procedure involving resurfacing of the femoral trochlea and the articular surface of the patella. Proper balance of the extensor mechanism must be done at the time of surgery to ensure correct tracking of the patella which in turn results in the best outcome for the replacement.
\end{abstract}

\section{Keywords}

Patellofemoral Arthroplasty, Patellar Maltracking, Patello Femoral Pain Lateral Retinacular Release, Tibial Tubercle Osteotomy

\section{Introduction}

Anterior knee pain is a common symptom in general orthopaedic practice and is reported in $8 \%$ of women and $2 \%$ of men over the age of 55 years. The treatment of isolated patellofemoral arthritis is controversial [1]. The etiology of the disease can be traumatic, secondary to malalignment, degenerative, idiopathic, or a combination of these. Many patients can be treated effectively with nonoperative means, including strengthening exercises, bracing, medications, and activity modifications. However, there are a group of patients with severe disease who are quite disabled and may require surgery.

Surgical treatment may be necessary in patients with chronic patellar subluxation, osteochondritis dissecans 
of the patella, excessive lateral pressure syndrome, or patellofemoral osteoarthritis [2].

Several surgical procedures have been used to treat the severely degenerated patellofemoral joint [3]. Osteotomy [4] [5], which realigns and transfers load across the patellofemoral articulation, debridement of osteophytes and chondrectomy combined with drilling of the subchondral bone, facetectomy, patellar reconstruction with periosteal grafts, patellectomy, or surface replacement of the patella alone, has been suggested as surgical options [5]-[15]. Total knee arthroplasty [16] [17] is another option for elderly, less active patients with severe, isolated patellofemoral arthritis. Each of these procedures, however, has its own limitations and may not be the treatment of choice for young active patients.

Patellofemoral arthroplasty was introduced in the 1950s [13]. There are many advantages of this procedure. It has had some favorable long-term results [18] [19]. It preserves the structural integrity of the joint [20]; and in one study [21], it was associated with a lower rate of deep venous thrombosis and pulmonary embolus compared with total knee arthroplasty. A patellofemoral arthroplasty can be revised to a total knee arthroplasty, and good results of such revisions have been reported [22].

The objective of the study is to assess the importance of extensor mechanism balancing for the success of patello femoral arthroplasty. We report the short-term results of patients with patellofemoral osteoarthritis who have been treated with a patellofemoral replacement.

\section{Method}

We studied the outcome of patellofemoral arthroplasty in 14 consecutive patients (17 knees) with isolated patellofemoral osteoarthritis treated between 2001 and 2007. No patient was lost to follow-up.

The inclusion criteria were patients who had objective evidence by radiographs of severe patellofemoral arthrosis with normal or nearly normal femorotibial compartments leading to severe discomfort in daily living, such as pain at rest with failed non operative management.

The exclusion criteria were infection, inflammatory arthritis, reflex sympathetic dystrophy, and psychogenic pain.

All patients had undergone a detailed history and physical examination along with any other tests considered appropriate by the operating surgeon (RR). The following radiographs were used: a full weight-bearing anteroposterior view, a lateral view, and a $45^{\circ}$ axial patellofemoral view [23] [24]. The patellar tracking was checked during pre op, intra op and assed post op clinically.

\subsection{Surgery}

All patients were positioned in a supine position with a lateral leg post and leg holder. All operations were performed under prophylactic antibiotic cover. A medial parapatellar approach was performed, the patella being everted laterally. Any osteophytes were removed from the femoral notch to prevent impingement of the cruciate ligaments.

Tracking of the patella was meticulously assessed after cementation of the prosthesis using the "no thumb technique". If there was any tendency to medial liftoff, a formal lateral retinacular release was performed. This was required in 7 of 17 operations (41.1\%), one patient had an osteotomy of the tibial tuberosity and one patient had bilateral iliotibial band lengthening. The patellar tracking was judged to be satisfactory at the end of all the procedures.

Drainage was removed within 24 hours. The patients were mobilized the first day after surgery supervised by a physiotherapist. Patients were allowed full weight bearing on the operated leg from the first postoperative day.

\subsection{Clinical Evaluation}

All patients were independently assessed clinically using the Oxford Knee score [25], the Knee Society score [26], and the Womac scoring system [27]. Patellar tracking was assessed clinically during follow up period.

\section{Results}

There were 14 patients (17 knees) in this group. Patient demographics are shown in Table 1. The implant which were used for the surgery are Link patellofemoral prosthesis and Low Contact Stress Patello-Femoral Joint, DePuy Orthopedics, Warsaw, IN and all-polyethylene dome shaped patella with three peg were used for the pa- 
Table 1. Patient demographics.

\begin{tabular}{cc}
\hline Numbers of Knees (N) & 17 \\
Gender M:F & $2: 12$ \\
Age & $69.9(54-88)$ \\
Side Rt:Lt & $7: 4$ \\
Bilateral & 6 \\
Diagnosis & 17-Osteoarthritis \\
Prosthesis & Link-8 \\
\end{tabular}

tella. Both of the femoral components are resurfacing types resecting minimal bone.

\subsection{Clinical Results}

The average arc of flexion was $110^{\circ}$ (range $85^{\circ}$ to $135^{\circ}$ ) preoperatively and $122^{\circ}$ (range $110^{\circ}$ to $130^{\circ}$ ) at the time of final follow up. All the clinical scores were found to improve post operatively (Table 2).

There were no incidence of infection and no clinical findings of patellar maltracking, subluxation or dislocation.

All fourteen patients (seventeen knees) reported no anterior pain during normal walking. No patient reported weakness, instability, or night pain. No patient required an assistive device to ascend or descend stairs.

\subsection{Radiographic Results}

At the time of final radiographic evaluation, no patient had evidence of patellar dislocation, component subsidence or pathological radiolucencies to suggest loosening.

Postoperative anteroposterior, lateral radiographs reveal proper component position and no evidence of patellar subluxation or dislocation.

\section{Discussion}

Patellofemoral pain is a common symptom in degenerate patellofemoral joints. Most patients can be treated conservatively by modification of activities, isometric quadriceps strengthening, and analgesics.

The symptoms may be modest and rarely produce severe disability. The natural history of the disease can extend over many years. Symptoms of sufficient severity to justify patellofemoral arthroplasty occur infrequently. Success depends upon many factors including the critical selection of the patient, balancing the extensor mechanism, and the choice of the patellofemoral implant. The results in the literature have varied. Blazina et al. [28] reported poor results with patellofemoral arthroplasty in a patient population with a mean age of 39 years. More than $50 \%$ of their patients required additional surgery within two years. They concluded, however, that patellofemoral arthroplasty was an acceptable alternative for older women with isolated arthritis. Arciero et al. [9] reported satisfactory results in $72 \%$ of their patients with a mean follow-up period of 5.2 years. Argenson, Guillaume and Aubaniac [21] had a success rate of $84 \%$ at 5.6 years.

Many studies have been conducted into numerous prosthesis that are currently on the market, all having varying degrees of success [15] [18] [19] [29]-[32]. These studies showed that failures were related to poor surgical technique, especially in relation to soft tissue balance, component alignment, persistent or recurrent patellar maltracking, the choice of implant or radiological progression of arthritis.

Patellofemoral replacement should always be carried out in conjunction with measures to obtain satisfactory alignment of the extensor mechanism [19] since persistent lateral malalignment, if not corrected, will cause lateral tilt, subluxation and early wear of the patellar button.

Lateral retinacular release was carried out in $41 \%$ in our series. This compares with $70 \%$ of the cases in the series of Cartier et al. [19] and 87.5\% of the series of Krajca-Radcliffe and Coker [31].

From our study, and in agreement with other studies, we feel that a patellectomy should only be considered as a salvage procedure in patellofemoral osteoarthritis or trauma [12] [33] [34]. Patellectomy is commonly asso- 
Table 2. Knee scores.

\begin{tabular}{ccc}
\hline & Preoperative scores & Last follow up scores \\
\cline { 2 - 3 } & Mean (range $)$ & Mean (range) \\
\hline WOMAC & $45.8(35-54)$ & $24.3(21-27)$ \\
Knee society score & $136.5(64-167)$ & $195(190-200)$ \\
Oxford knee score & $24(20-28)$ & $11.2(10-12)$ \\
\hline
\end{tabular}

ciated with weakness of extension and patients often do not achieve complete relief of pain with this procedure [34]-[36].

The purpose of this paper is not to determine long term survival of implants used in patella-femoral replacement. This has been shown in previous published literature. This paper is written to emphasize the need for correction of patella maltracking at the time of surgery. This is particularly important where the patellofemoral arthritis is secondary to dysplasia and the patella may be maltracking for the patient's lifetime. Correction at the time of surgery of the tibial tubercle malposition or an overly tight iliotibial band is important to reduce the need for reoperation. Medial patellofemoral ligament reconstruction may be required if deficient.

The limitations of the study are no cohort to compare the outcome and small number of patient group.

\section{Conclusion}

We conclude that patellofemoral arthroplasty can give satisfactory results in suitably selected patients. The operation should be viewed as a combined soft-tissue procedure involving resurfacing of the femoral trochlea and the articular surface of the patella. Proper balance of the extensor mechanism must be done at the time of surgery to ensure correct tracking of the patella.

\section{References}

[1] McAlindon, T.E., Snow, S., Cooper, C. and Dieppe, P.A. (1992) Radiographic Patterns of Osteoarthritis of the Knee Joint in the Community: The Importance of the Patellofemoral Joint. Annals of the Rheumatic Diseases, 51, 844-849. http://dx.doi.org/10.1136/ard.51.7.844

[2] Fulkerson, J.P. (1997) Surgical Treatment of Patellofemoral Chondrosis and Arthrosis. In: Fulkerson, J.P., Ed., Disorders of the Patellofemoral Joint, 3rd Edition, Williams \& Wilkins, Baltimore, 299-336.

[3] Lonner, J.H. (2003) Patellofemoral Arthroplasty. Techniques in Knee Surgery, 2, 144-152. http://dx.doi.org/10.1097/00132588-200309000-00003

[4] Fulkerson, J.P. (1983) Anteromedialization of the Tibial Tuberosity for Patellofemoral Malalignment. Clinical Orthopaedics and Related Research, 177, 176-181.

[5] Maquet, P. (1979) Mechanics and Osteoarthritis of the Patellofemoral Joint. Clinical Orthopaedics and Related Research, 144, 70-73.

[6] Radin, A.L. and Pan, H.Q. (1993) Long-Term Follow-Up Study on the Maquet Procedure with Special Reference to the Causes of Failure. Clinical Orthopaedics, 290, 253-258.

[7] Sakai, N., Koshino, T. and Okamoto, R. (1996) Pain Reduction after Anteromedial Displacement of the Tibial Tuberosity: 5-Year Follow-Up in 21 Knees with Patellofemoral Arthrosis. Acta Orthopaedica Scandinavica, 67, 13-15. http://dx.doi.org/10.3109/17453679608995601

[8] Schmid, F. (1993) The Maquet Procedure in the Treatment of Patellofemoral Osteoarthritis: Long-Term Results. Clinical Orthopaedics, 294, 254-258.

[9] Arciero, R.A. and Toomey, H.E. (1988) Patellofemoral Arthroplasty: A Three- to Nine-Year Follow-Up Study. Clinical Orthopaedics, 236, 60-71.

[10] Martens, M. and De Rycke, J. (1990) Facetectomy of the Patella in Patellofemoral Osteoarthritis. Acta Orthopaeligdica Belgica, 56, 563-567.

[11] Hoikka, V.E.J., Jaroma, H.J. and Ritsilä, V.A. (1990) Reconstruction of the Patellar Articulation with Periosteal Grafts: 4-Year Follow-Up of 13 Cases. Acta Orthopaedica, 61, 36-39. http://dx.doi.org/10.3109/17453679008993062

[12] Picket, J.C. and Stoll, D.A. (1979) Patellaplasty or Patellectomy? Clinical Orthopaedics and Related Research, 144, 103-106. 
[13] McKeever, D.C. (1955) Patellar Prosthesis. Journal of Bone and Joint Surgery, 37A, 1074-1084.

[14] Insall, J.N., Tria, A.J. and Aglietti, P. (1980) Resurfacing of the Patella. Journal of Bone and Joint Surgery, 62A, 933936.

[15] Harrington, K.D. (1992) Long-Term Results for the McKeever Patellar Resurfacing Prosthesis Used as a Salvage Procedure for Severe Chondromalacia Patellae. Clinical Orthopaedics and Related Research, 279, 201-213.

[16] Laskin, R.S. and van Steijn, M. (1999) Total Knee Replacement for Patients with Patellofemoral Arthritis. Clinical Orthopaedics and Related Research, 367, 89-95.

[17] Mont, M.A., Haas, S., Mullick, T. and Hungerford, D.S. (2002) Total Knee Arthroplasty for Patellofemoral Arthritis. Journal of Bone and Joint Surgery, 84, 1977-1981.

[18] Kooijman, H.J., Driessen, A.P. and van Horn, J.R. (2003) Long-Term Results of Patellofemoral Arthroplasty. A Report of 56 Arthroplasties with 17 Years of Follow-Up. The Bone Joint Journal, 85, 836-840.

[19] Cartier, P., Sanouiller, J.L. and Grelsamer, R. (1990) Patellofemoral Arthroplasty. 2-12-Year Follow-Up Study. The Journal of Arthroplasty, 5, 49-55. http://dx.doi.org/10.1016/S0883-5403(06)80009-4

[20] Blazina, M.E., Anderson, L.J. and Hirsh, L.C. (1990) Patellofemoral Replacement: Utilizing a Customized Femoral Groove Replacement. Techniques in Orthopaedics, 5, 53-55. http://dx.doi.org/10.1097/00013611-199004000-00009

[21] Argenson, J.N., Guillaume, J.M. and Aubaniac, J.M. (1995) Is There a Place for Patellofemoral Arthroplasty? Clinical Orthopaedics and Related Research, 321, 162-167.

[22] Sisto, D.J. and Cook, D.L. (1997) Total Knee Replacement in Patients with a Failed Patellofemoral Replacement. Orthop Trans., 21, 115.

[23] Merchant, A.C., Mercer, R.L., Jacobsen, R.H. and Cool, C.R. (1974) Roentgenographic Analysis of Patellofemoral Congruence. Journal of Bone and Joint Surgery, 56, 1391.

[24] Merchant, A.C. (2001) Patellofemoral Imaging. Clinical Orthopaedics and Related Research, 15-21.

[25] Dawson, J., Fitzpatrick, R., Murray, D. and Carr, A. (1998) Questionnaire on the Perceptions of Patients about Total Knee Replacement. Journal of Bone and Joint Surgery, 80B, 63-69.

[26] Insall, J.N., Dorr, L.D., Scott, R.D. and Scott, W.N. (1989) Rationale of the Knee Society Clinical Rating System. Clinical Orthopaedics and Related Research, 248, 13-14.

[27] Bellamy, N., Buchanan, W.W., Goldsmith, C.H., Campbell, J. and Stitt, L.W. (1998) Validation Study of WOMAC: A Health Status Instrument for Measuring Clinically Important Patient Relevant Outcomes to Antirheumatic Drug Therapy in Patients with Osteoarthritis of the Hip or Knee. The Journal of Rheumatology, 15, 1833-1840.

[28] Blazina, M.E., Fox, J.M., Del Pizzo, W., Broukhim, B. and Ivey, F.M. (1979) Patellofemoral Replacement. Clinical Orthopaedics and Related Research, 144, 98-102.

[29] Tauro, B., Fellow, K., Ackroyd, C.E., Newman, J.H. and Shah, N.A. (2001) The Lubinus Patello-Femoral Arthroplasty. A Five- to Ten-Year Prospective Study. Journal of Bone and Joint Surgery, 83B, 696-701. http://dx.doi.org/10.1302/0301-620X.83B5.11577

[30] Smith, A.M., Peckett, W.R.C., Butler-Manuel, P.A., Venu, K.M. and D’Arcy, J.C. (2002) Treatment of Patello-Femoral Arthritis Using the Lubinus Patello-Femoral Artroplasty. A Retrospective Review. The Knee, 9, 27-30. http://dx.doi.org/10.1016/S0968-0160(01)00127-2

[31] Krajca-Radcliffe, J. and Coker, T.P. (1996) Patello-Femoral Arthroplasty. A 2- to 18-Year Follow-Up Study. Clinical Orthopaedics and Related Research, 330, 143-151.

[32] Ackroyd, C.E. and Newman, J.H. (2001) The Avon Patellofemoral Arthroplasty—Development and Early Results. Journal of Bone and Joint Surgery, 83B, 146.

[33] Kelly, M.A. and Brittis, D.A. (1992) Patellectomy. Orthopedic Clinics of North America, 23, 657-663.

[34] Bullek, D.D. and Kelly, M.A. (1995) Management of Patellofemoral Arthritis. In: Scuderi, G.R., Ed., The Patella, Springer-Verlag, New York, 291-308. http://dx.doi.org/10.1007/978-1-4612-4188-1_15

[35] Kaufer, H. (1979) Patellar Biomechanics. Clinical Orthopaedics and Related Research, 144, 51-54.

[36] Martin, S.D., Haas, S.B. and Insall, J.N. (1995) Primary Total Knee Arthroplasty after Patellectomy. Journal of Bone and Joint Surgery, 77A, 1323-1330. 
Scientific Research Publishing (SCIRP) is one of the largest Open Access journal publishers. It is currently publishing more than 200 open access, online, peer-reviewed journals covering a wide range of academic disciplines. SCIRP serves the worldwide academic communities and contributes to the progress and application of science with its publication.

Other selected journals from SCIRP are listed as below. Submit your manuscript to us via either submit@scirp.org or Online Submission Portal.
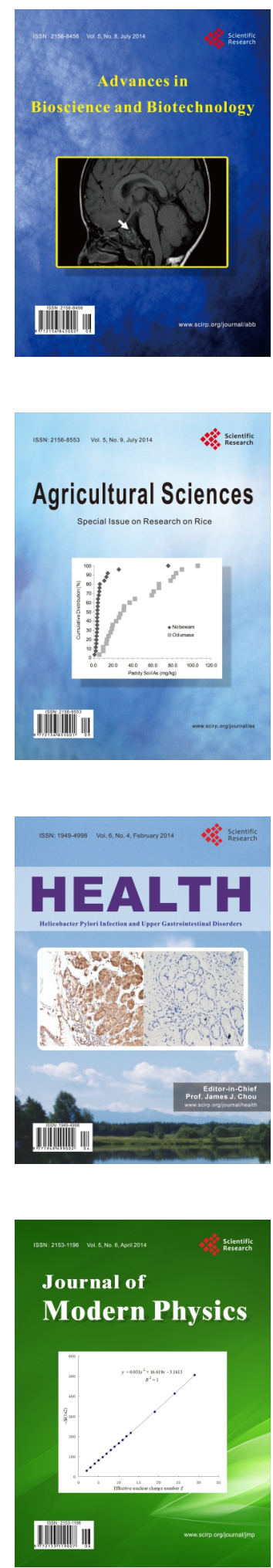
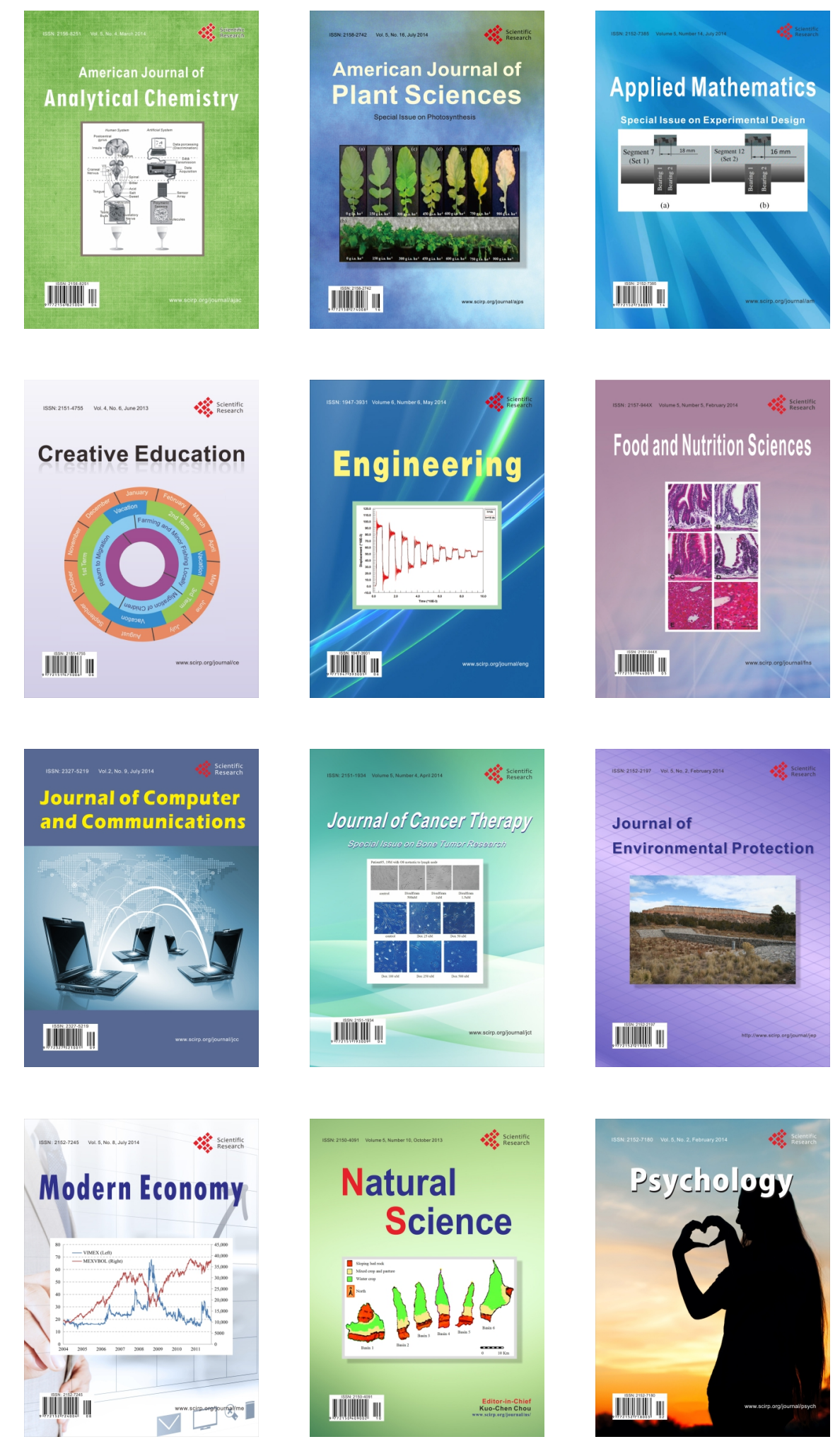